\title{
Nitroxoline: repurposing its antimicrobial to antitumor application*
}

\author{
Ana Mitrović $1 \otimes$ and Janko Kos $1,2 \square$ \\ 1Department of Biotechnology, Jožef Stefan Institute, 1000 Ljubljana, Slovenia; 2Faculty of Pharmacy, University of Ljubljana, 1000 Ljubljana, \\ Slovenia
}

\begin{abstract}
Cancer is a disease receiving an outstanding input of funds for basic and clinical research but is, nevertheless, still the second leading cause of death in the developed world and a great burden for health systems. New drugs are therefore needed to improve therapy, prolong survival of cancer patients and improve their quality of life. The high cost of development and clinical evaluation of new drugs limits the number that actually enter clinical use. To overcome this problem, repurposing of established drugs for new indications has gained a lot of interest, especially in the field of oncology. The well-established antimicrobial agent nitroxoline has been identified as a promising candidate to be repurposed for cancer treatment in several independent studies. Here we have reviewed a wide range of molecular mechanisms and tumor models involving nitroxoline in impairment of tumor progression. Furthermore, nitroxoline was used as a lead compound for structure-based chemical synthesis of new derivatives in order to improve its potency as well as selectivity for various targets. The potent antitumor activity of nitroxoline points strongly in the direction of its repurposing for cancer treatment and to the benefits of this strategy for patients and healthcare system.
\end{abstract}

Key words: drug repurposing, nitroxoline, cancer, antitumor therapy, drug discovery

Received: 05 November, 2019; revised: 06 December, 2019; accepted: 06 December, 2019; available on-line: 13 December, 2019

\e-mail: ana.mitrovic@ijs.si (AM), janko.kos@ffa.uni-lj.si (JK)

*Acknowledgements of Financial Support:

The costs of the article published as a part of the 44th FEBS Congress Kraków 2019 - From molecules to living systems block are financed by the Ministry of Science and Higher Education of the Republic of Poland (Contract 805/P-DUN/2019).

This work was supported by Slovenian Research Agency grant numbers Z3-9273 to A.M. and J4-8227 and P4-0127 to J.K.

Abbreviations: AMPK, AMP-activated protein kinase; BET, bromodomain and extraterminal family; BRD4, bromodomain-containing protein 4; BRD4_BD1, the first bromodomain of BRD4; BRD4LGR , bromodomain-containing protein 4-specific score based virtual screening protocol; BSA, bovine serum albumin; CDK, cyclin dependent kinase; ECM, extracellular matrix; FOXM1, Forkhead box protein M1; HTS, high-throughput screen; HUVEC, human umbilical vein endothelial cells; MDM2, human homologue of mouse double minute 2; MDSCs, myeloid-derived suppressor cells; MetAP2, Type 2 methionine aminopeptidase; MMP, metalloproteinase; mTOR mammalian target of rapamycin; NAD, nicotinamide adenine dinucleotide; PARP, poly(ADP-ribose) polymerase; PD-L1, programmed death-ligand 1; PI3K Phosphatidyl inositol-3 kinase; SAR, structureactivity relationship; SCLC, small-cell lung cancers; 2; SIRT1, Sirtuin-1; TRIM25 triple motif containing 25; TUNEL, deoxynucleotide transferase-mediated dUTP nick-end labeling staining

\section{INTRODUCTION}

Cancer is the second leading cause of death worldwide. According to the World Health Organization (WHO) it was responsible for 9.6 million of deaths in 2018 (WHO, 2019). Besides threatening health cancer also has a significant social and increasing economic impact (WHO, 2019). Despite advances in understanding the processes and mechanisms involved in cancer development and progression, together with a series of new antitumor therapies involved in clinical practice in the past decades, successful combat with cancer still remains a challenge that needs to be addressed (Gupta et al., 2013).

One of the major problems of current conventional anticancer therapies is the number of severe off target effects that result in a decrease in the quality of life for cancer patients (Shim \& Liu, 2014). In addition, most of the currently used anticancer drugs are highly expensive providing minimal increase in the overall survival (Gupta et al., 2013). Unfortunately, regardless of large investments in drug development, the number of new drugs available on the market has decreased over the past decade due to the increasing cost of their development ( $\mathrm{Ya}$ dav \& Talwar, 2019).

In contrast to de novo development of new medicines, drug repurposing represents an alternative way of improving success rate, shortening processing time and cutting costs of cancer drug development (Sleire et al., 2017; Hernandez et al., 2017). Drug repurposing, also known as drug repositioning, reprofiling, redirecting or retasking, is a drug development strategy of finding new indications for already licensed or failed drugs apart from its original indication (Pantziarka et al., 2014; Yadav \& Talwar, 2019; Sleire et al., 2017; Hernandez et al., 2017; Fong \& To, 2019). The main advantage of repurposed drugs is that they already have known and well-established toxicological profiles, tolerability, pharmacokinetics and pharmacodynamic data (Nowak-Sliwinska et al., 2019; Fong \& To, 2019; Gupta et al., 2013; Sleire et al., 2017; Hernandez et al., 2017). Furthermore, existing drugs have already known dosing regimen, pharmacology and interactions with other drugs (Nowak-Sliwinska et al., 2019; Gupta et al., 2013; Sleire et al., 2017; Hernandez et al., 2017).

For these reasons drug repurposing reduces the time frame and costs of development as well as allowing quick translation into clinical trials, since preclinical studies and formulation have already been performed. Furthermore, due to the well-established dosing, safety and toxicity profile of the existing drugs, drug repurposing usually raises fewer safety concerns and their use for new indications is thus usually approved sooner and at a 
higher success rate (Fong \& To, 2019; Gupta et al., 2013; Sleire et al., 2017; Hernandez et al., 2017).

Drug repurposing for novel indication includes identification of potential drug candidates, a mechanistic investigation of preclinical models, together with safety and efficacy assessment in clinical trials (Fong \& To, 2019; Hernandez et al., 2017). The latter are, regardless of previous usage, still necessary, when the drug is being used or repurposed for a new indication, since the new application may be accompanied by previously unknown side effects (Sleire et al., 2017). As for already known and used drugs, extensive data are available, especially for pharmacokinetic and pharmacodynamic properties (Sleire et al., 2017; Gupta et al., 2013) and, since such drugs have already undergone preclinical and Phase I clinical studies, they can be translated more rapidly into Phase II and Phase III clinical studies (Gupta et al., 2013). Ideal candidates for drug repurposing are also compounds that have undergone clinical trials where they were shown to be safe, but have failed for other reasons (Hernandez et al., 2017).

Drug repurposing is of special interest, especially in the field of oncology (Shim \& Liu, 2014; Sleire et al., 2017; Fong \& To, 2019). Antitumor efficacy was shown for a number of compounds from the wide range of drug classes used for indications other than cancer treatment. Examples of such drugs are thalidomide, metformin, acetylsalicylic acid, statins, raloxifene, tamoxifen and many other, which displayed different molecular mechanisms of antitumor activity (Sleire et al., 2017). Different strategies can be used to identify and implement currently used drugs in order to repurpose for cancer treatment. Repurposing for cancer treatment can be based either on their well-known biological activity that points logically towards their anticancer treatment, i.e. drugs such as thalidomide, acetylsalicylic acid, metformin, valproic acid and others, or they can be identified from a set of arbitrarily chosen drugs examined for their specificity for defined cancer target such as nitroxoline and noscapine (Gupta et al., 2013).

In this review we have focused on and discussed the possibilities of using the well-established antimicrobial agent nitroxoline in cancer treatment, together with reviewing the mechanisms of its involvement in antitumor activity. We also present an overview of new derivatives prepared by focused chemical synthesis based on nitroxoline structure and available data relating to its interaction with variety of targets in order to further improve its antitumor action and also to explore the structural requirements needed for its binding to different targets.

\section{NITROXOLINE IN CLINICAL PRACTICE - AN ANTIMICROBIAL AGENT}

Nitroxoline (5-nitro-8-hydroxyquinoline) is a wellestablished antimicrobial agent used for treatment and prophylaxis of urinary tract infections. It was first described in the fifties of the last century and then started to be used as an antibiotic. Nitroxoline is active against most Gram-negative and Gram-positive uropathogenic bacteria, mycoplasmas ( $M$. hominis, Ureaplasma urealyticum) and the human pathogenic Candida spp. Its antibacterial activity against Acinetobacter spp., Enterococcus spp., and Serratia $s p p$. is variable while Psendomonas $s p p$. is considered to be resistant. Oral administration of nitroxoline showed good safety with only a few tolerable side effects (Naber et al., 2014). Despite long time of its clinical use still no increase of resistance of uropathogens against nitroxoline has been observed. For example, nitroxoline showed no decrease of activity against E. coli, regardless of their broad resistance profiles towards other antimicrobial agents used in clinical practice for treatment of urinary tract infections (Kresken \& Körber-Irrgang, 2014; Naber et al., 2014).

The antimicrobial activity mode of action of nitroxoline is related mainly to its ability to chelate various bivalent metallic ions. It has been proposed that it interacts with $\mathrm{Mg}^{2+}$, stabilizing the lipopolysaccharide molecules that form the outer bacterial membrane. As a result, the bacterial surface becomes more hydrophobic, decreasing adherence to the catheter surface. The reduced antibacterial activity of nitroxoline in the presence of $\mathrm{Mn}^{2+}$ and $\mathrm{Mg}^{2+}$, but not of $\mathrm{Ca}^{2+}, \mathrm{Na}^{+}$or $\mathrm{K}^{+}$, also confirms this mode of action (Pelletier et al., 1995; Oviedo et al., 2000; Naber et al., 2014). By chelating bivalent cations essential for RNA synthesis, nitroxoline selectively and rapidly inhibits RNA synthesis in yeast during cell division (Fraser \& Creanor, 1974; Naber et al., 2014). Moreover, nitroxoline inhibits bacterial adhesin and the attachment already in subinhibitory concentrations (Naber et al., 2014). Additionally, nitroxoline has been identified as an antibiofilm agent, since it is able of chelating $\mathrm{Zn}^{2+}$ and $\mathrm{Fe}^{2+}$ from the biofilm matrix (Sobke et al., 2012; Naber et al., 2014). Bacterial biofilms constitute surface-attached bacteria colonies that consist of slow-growing or nonreplicating bacteria that exhibit higher toleration of most of the conventional antibiotics and are also, in many cases, responsible for recurrence of infections and for chronic infections (Abouelhassan et al., 2017). Nitroxoline inhibits formation of Pseudomonas aeruginosa biofilms and induces dispersion of bacteria as well as reducing the thickness of already established biofilms (Sobke et al., 2012). Again, sub-inhibitory concentrations of nitroxoline are sufficient to inhibit biofilm formation and adhesion of uropathogenic bacteria to uroepithelial cells and urinary catheters (Sobke et al., 2012; Kresken \& KörberIrrgang, 2014).

Due to its long time use in clinical practice, the pharmacokinetic and pharmacodynamic properties of nitroxoline are well established. It is administered orally, the standard dose of nitroxoline used in treatment of urinary tract infections being $250 \mathrm{mg}$ per 8h (Mrhar et al., 1979; Wagenlehner et al., 2014; Naber et al., 2014; Wijma et al., 2018). After administration, complete and rapid adsorption of nitroxoline in the urinary tract was observed (Wijma et al., 2018; Mrhar et al., 1979). Following adsorption, nitroxoline is excreted in the urine, either in unconjugated or, more commonly, in metabolized conjugated forms such as glucuronide or sulfate (Mrhar et al., 1979; Wagenlehner et al., 2014; Naber et al., 2014). The antibacterial urinary activity of nitroxoline can be observed soon after administration of a single dose. In urine, nitroxoline exhibits mainly bacteriostatic activity, its antimicrobial activity being higher in acidic than in alkaline urine (Wagenlehner et al., 2014; Naber et al., 2014).

Given the increasing problem of bacterial resistance against most standard antibiotics, interest in the use of nitroxoline for treating infections has again increased over recent years (Kresken \& Körber-Irrgang, 2014; Naber et al., 2014; Wagenlehner et al., 2014). In a study where the antimicrobial effect of different 8-hydroxyquinolines, including nitroxoline, against a large number of microorganisms was evaluated, nitroxoline showed the most potent activity against most Gram-negative bacteria and was also effective against Gram-positive bacteria, exhibiting activity comparable to that of 8-hydroxyquinoline. On the other hand, despite its ability to chelate bivalent 
cations, nitroxoline did not show antioxidative activity. Of the different 8-hydroxyquinoline derivatives, one with an amino group at position 5 was the most potent antioxidant. The loss of antioxidant activity of nitroxoline compared to that of other compounds can be attributed to the presence of the strong electron withdrawing nitro group at position 5. Nevertheless, these results indicate that nitroxoline and its derivatives are suitable for use as antimicrobial agents for indications other than treatment of urinary tract infections (Cherdtrakulkiat et al., 2016). The broad antimicrobial spectrum of nitroxoline and, in general, the absence of resistance, was also observed in a recent study where the susceptibility to nitroxoline was tested against a large number of urinary clinical isolates, including those exhibiting multidrug resistance (Sobke et al., 2018). Additionally, nitroxoline has been recognized as exhibiting broad-spectrum biofilm eradication activity against several human pathogens, including those resistant to most other antimicrobial agents (Abouelhassan et al., 2017). Together these findings suggest novel applications for the use of nitroxoline in the treatment of bacterial infections (Cherdtrakulkiat et al., 2016; Sobke et al., 2018; Abouelhassan et al., 2017).

\section{ANTITUMOR ACTIVITY OF NITROXOLINE}

To date, there have been a number of reports describing nitroxoline antitumor activity (Fig. 1). For the first time its antitumor activity was identified in a search for Type 2 methionine aminopeptidase (MetAP2) inhibitors as novel antiangiogenic agents by Shim and coworkers (Shim et al., 2010). Interestingly, nitroxoline was also identified independently as a hit in a high-throughput screen (HTS) of a commercially available compound library of 175000 compounds that was also screened for identification of new MetAP2 inhibitors (Jiang et al., 2011).

Angiogenesis is the process of formation of new blood vessels that is essential for the growth of primary solid tumors beyond 1-2 $\mathrm{mm}$ in diameter. It enables spread of tumor cells to distant sites and formation of metastasis and tumor progression. Angiogenesis is a complex multistep process that includes proliferation of endothelial cells, degradation of extracellular matrix (ECM), migration of endothelial cells through remodeled ECM and tube formation by endothelial cells (Dallinga et al., 2018; Sato, 2004). MetAP2 has been shown to play an important role in endothelial cell proliferation (Ehlers et al., 2016; Sato, 2004). MetAP2 is a ubiquitously expressed intracellular metallopeptidase that catalyzes the removal of $\mathrm{N}$-terminal methionine during maturation of proteins and polypeptides, facilitating their translocation from the ribosomes (Mauriz et al., 2010; Sato, 2004; Shim et al., 2010). It has been identified as an important molecular target for angiogenesis inhibitors which are able to suppress endothelial cell proliferation (Sato, 2004).

Sirtuin-1 (SIRT1) is a member of the sirtuin (SIRT) family, a group of the silent information regulator 2 (SIR2) family of nicotinamide adenine dinucleotide (NAD)-dependent deacetylases (Lee et al., 2019; Brooks \& $\mathrm{Gu}, 2009)$. SIRT1 catalyzes the removal of acetyl groups from different non-histone targets (Brooks \& Gu, 2009). The SIRT family consists of seven isoform members, each having a different subcellular localization, enzymatic activity and substrate specificity. SIRTs regulate a number of cellular processes including cell metabolism, cell survival and DNA repair (Lee et al., 2019). SIRT1 is predominantly a nuclear protein (Lee et al., 2019; Brooks \&
Gu, 2009). During cancer progression it regulates histone deacetylation (Liu et al., 2009) and has an important repressive effect on tumor suppressor p53 and other genes involved in the stress response. It enables DNA repair following DNA damage and opposes apoptosis induction (Brooks \& Gu, 2009; Ota et al., 2007). By functional interaction with p53 and other biological targets, SIRT1 delays cellular senescence and has an important function in life span extension, DNA repair and cell cycle arrest (Brooks \& Gu, 2009; Ota et al., 2007; Liu et al., 2009). It also blocks cell differentiation and stress induced apoptosis, while promoting cell growth, angiogenesis and vasodilatation (Liu et al., 2009; Ota et al., 2007). Inhibition of SIRT1 promotes premature senescence in endothelial cells by upregulating the level of acetylated p53 (Ota et al., 2007), resulting in inhibition of angiogenesis (Lee et al., 2019). SIRT1 is, therefore, a promising target for inhibition of angiogenesis (Liu et al., 2009; Shim et al., 2010).

The study of Shim and others (Shim et al., 2010) shows that nitroxoline is a potent inhibitor of MetAP2 in vitro, thus inhibiting endothelial cell proliferation and tube formation, both in vitro and in vivo. Moreover, it reduces tumor volume in breast cancer xenografts and inhibits growth of bladder cancer as shown in an orthotopic mouse model. Further, nitroxoline inhibits SIRT1 and induces an increase in the level of acetylated p53. Thus, nitroxoline is a dual inhibitor of MetAP2 and SIRT1, with the synergistic effect of inducing senescence and inhibiting HUVEC proliferation. It was therefore suggested as a potent inhibitor of angiogenesis (Shim et al., 2010).

Independently, nitroxoline was identified as a potent and reversible non-covalent inhibitor of cathepsin B in a high-throughput screening followed by biological evaluation of the best ranked compounds (Mirković et al., 2011).

Cathepsin B is a lysosomal cysteine peptidase that has an important role in a number of physiological processes. Its dysregulation is associated with a variety of pathological processes. During cancer progression, it acts as a tumor promoting factor, contributing to the degradation of ECM, a crucial step that promotes tumor migration and invasion and enables metastasis and angiogenesis (Kos et al., 2014; Mohamed \& Sloane, 2006; Vasiljeva et al., 2007; Joyce \& Hanahan, 2004). It can degrade ECM proteins, either directly or indirectly, via activation of other peptidases downstream in a proteolytic cascade (Roshy et al., 2003; Skrzydlewska et al., 2005). The presence of the extra structural element, termed the occluding loop, designates cathepsin B as being unique among cysteine cathepsins (Musil et al., 1991; Nägler et al., 1997; Illy et al., 1997; Krupa et al., 2002; Almeida et al., 2001). The conformation of the flexible occluding loop determines whether the enzyme acts as an endopeptidase or as an exopeptidase (carboxydipeptidase) (Nägler et al., 1997; Krupa et al., 2002; Almeida et al., 2001). Using a range of research tools including cathepsin B-specific inhibitors, siRNAs, and tumor mouse models deficient in cathepsin B or overexperessing cathepsin B, cathepsin $\mathrm{B}$ has been validated as a promising and druggable target for treating cancer (Mirković et al., 2015; Vasiljeva \& Turk, 2008; Gocheva et al., 2006).

Nitroxoline inhibits cathepsin B endopeptidase activity selectively in the low micromolar range. The $\mathrm{x}$-ray crystal structure of the nitroxoline/cathepsin B complex revealed that nitroxoline binds to the primed site of the active site cleft. The aromatic quinoline rings fill the S2' binding site of cathepsin B and the negatively charged group interacts specifically with the positively charged 


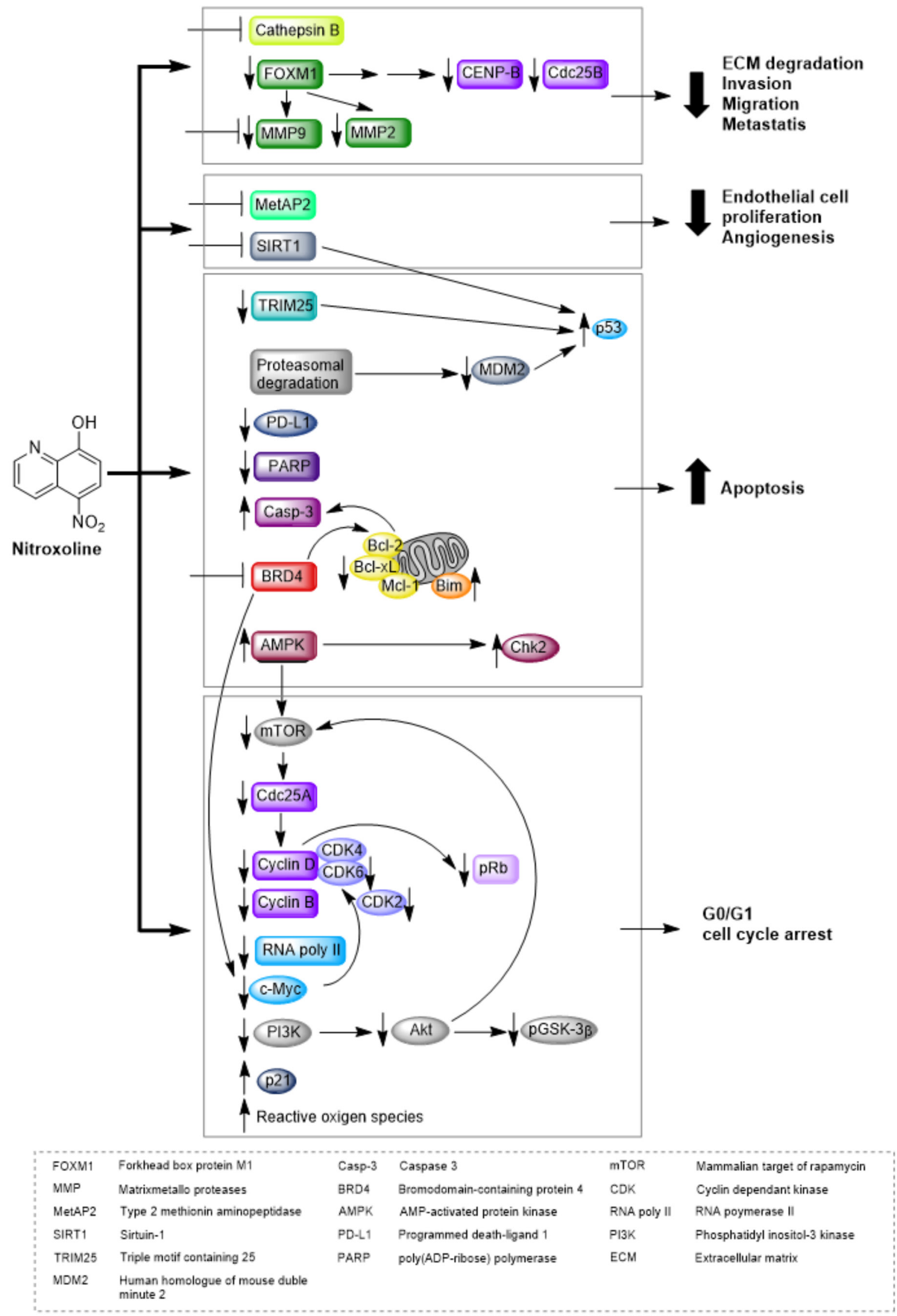

Figure 1. Schematic representation of the molecular mechanisms of nitroxoline antitumor activity.

Nitroxoline inhibits tumor progression by impairing tumor invasion, migration and angiogenesis, as well as by inducing cell cycle arrest and apoptosis. 
His110 and His111 groups from the occluding loop that are essential for the binding of substrates to the active site cleft (Mirković et al., 2011). Using a wide range of functional assays, it was shown that nitroxoline reduces significantly the degradation of ECM, tumor cell invasion and endothelial tube formation in vitro in a number of cell lines. Moreover, nitroxoline significantly abrogates tumor growth and metastasis formation in vivo in tumor mice models (Mirković et al., 2015).

Furthermore, nitroxoline, as an antitumor agent, was shown to be more cytotoxic against human cancer cells than other 8-hydroxyquinoline analogues. Its cytotoxicity was enhanced by the addition of copper. In this study, it was also shown that nitroxoline cytotoxicity is associated with increase in reactive oxygen species, although it does not affect intracellular zinc concentration as clioquinol does (Jiang et al., 2011).

Next, nitroxoline can act as an antiproliferative agent against malignant glioma cells in vitro in a time and dose dependent manner. Further, it induces cell cycle arrest and apoptosis in a dose-dependent manner. At low doses treatment with nitroxoline leads to G0/G1 cell-cycle arrest, while higher doses result in apoptosis via the expression of caspase 3 and cleavage of poly(ADP-ribose) polymerase (PARP). Increased apoptosis after nitroxoline treatment was also observed in the PTEN/KRAS gliomas in vivo in a genetically engineered mouse glioma model that spontaneously developes grade III gliomas (Lazovic et al., 2015). Here tumor volume was not increased significantly in nitroxoline treated mice after 14 days of treatment and histological analysis showed larger number of cells positive for deoxynucleotide transferasemediated dUTP nick-end labeling staining (TUNEL) (Lazovic et al., 2015) that detects apoptotic cells that undergo extensive DNA degradation during the late stages of apoptosis (Kyrylkova et al., 2012) compared with the control group, in which tumor volumes also were increased significantly (Lazovic et al., 2015).

Further, an effect of nitroxoline was also observed on glioblastoma when the early therapeutic response was monitored in a temozolamide (TMZ) resistant glioblastoma multiforme mouse model, using amide proton transfer (ATP) imaging as a novel method of imaging and detecting an early therapeutic response in glioblastoma patients (Kumari et al., 2019).

Moreover, nitroxoline was found to induce apoptosis in multiple myeloma (Mao et al., 2017). Similar to that as in glioma cells, treatment of multiple myeloma cell lines with nitroxoline activated caspase 3 in a concentrationdependent manner and caused cleavage and inactivation of PARP, as well as of deactivated survival proteins such as Bcl-xL and Mcl-1. Additionally, in multiple myeloma, nitroxoline was suggested to affect apoptosis by concentration-dependent downregulation of a triple motif containing 25 (TRIM25)/p53 axle (Mao et al., 2017). The protein encoded by the TRIM25 gene is a member of the tripartite motif (TRIM) family ubiquitin ligases. It is an ubiquitously expressed cytoplasmic protein and catalyzes the addition of ubiquitin moieties to the target protein (Heikel et al., 2016). TRIM 25 was originally identified as an estrogen-responsive gene, but the protein has been found to be overexpressed in several types of cancer including breast, ovarian, gastric and lung, in which it has been implicated in cell proliferation (Heikel et al., 2016; Qin et al., 2016). It was shown that nitroxoline treatment downregulates TRIM25 and upregulates p53 levels since the decrease in TRIM25 prevented polyubiquination and degradation of p53. However, nitroxoline did not affect the levels of PTEN (Mao et al., 2017).
The effect of nitroxoline on cell-cycle arrest and apoptosis was also confirmed in prostate cancer cells (Chang et al., 2015). Nitroxoline induced G1 cell-cycle arrest on both hormone-sensitive and hormone-refractory prostate cancers. It was suggested that nitroxoline treatment induces G1 cell-cycle arrest in prostate cancer cells by inhibiting the cyclin D1-Rb-Cdc25A axis that is responsible for the progression of G1 phase of cell cycle. Treatment with nitroxoline caused a time-dependent decrease in the expression of cyclin D1 that is, together with its catalytic partner Cdk4, the key player in G1 phase progression. Further, decrease in cyclin D1 results in lower phosphorylation of $\mathrm{Rb}$ protein, a tumor suppressor responsible for the G1 checkpoint that blocks the entry of cells to the $\mathrm{S}$ phase and to cell cycle progression. Nitroxoline also decreases expression of $\mathrm{Cdc} 25 \mathrm{~A}$ protein, a member of Cdc 25 family of dual-specificity phosphatases that is induced during the G1 phase and is required for entry to the $\mathrm{S}$ phase. This study has shown that a key function in the induction of apoptosis by nitroxoline in prostate cancer is attributed to activation of the cell energy sensor and signal transducer AMP-activated protein kinase (AMPK). Nitroxoline effects G1 cell-cycle arrest via the cyclin $\mathrm{D} 1-\mathrm{Rb}-\mathrm{Cdc} 25 \mathrm{~A}$ axis by activating AMPK, which is a both concentration and time dependent step, thus inhibiting the downstream effector mTOR signaling pathway. In this pathway various cellular processes, including transcription and translation, are regulated. It is crucial for cell proliferation, growth, survival and metabolism, and effects G1 cell-cycle arrest via the cyclin D1-Rb-Cdc25A axis. Moreover, nitroxoline contributes to cell apoptosis by inducing AMPK dependent activation of Chk2 that encodes a serine/threonine kinase that coordinates cell responses to DNA damage (Chang et al., 2015). On the other hand, through the AMPK pathway, nitroxoline also induces autophagy, resulting in a decreased effect on apoptosis (Chang et al., 2015).

Nitroxoline was shown to reduce the viability of the prostate cancer cells, RM9-Luc-PSA, LNCaP, DU145 and PC3 (Xu et al., 2019). No significant toxicity, however, was observed in normal prostate cells, RWPE-1. In mouse prostate cancer cells, RM9-Luc-PSA nitroxoline also reduced cell proliferation and, in line with the previous study, induced cell cycle arrest, as shown by the reduced number of cells in the G0/G1 phase and reduced expression of CDK2, CDK6 and cyclin D3. Furthermore, nitroxoline inhibited the $\mathrm{PI} 3 \mathrm{~K} / \mathrm{Akt}$ signaling pathway in which levels of phospho-PI3 kinase, pAkt (Thr308 and Ser473) and pGSK-3 $\beta$ were lower. Similarly, as observed in multiple myeloma and in prostate cancer cells, nitroxoline induced cell apoptosis and decreased expression of the apoptosis related proteins $\mathrm{Bcl}$ 2 and Bcl-xL as well as increasing cleavage of the major executive apoptotic enzyme, caspase-3, in RM9-Luc-pSA cells. Nitroxoline also downregulated expression of programmed death-ligand 1 (PD-L1) in prostate cell lines and in tumor tissue. The effect of nitroxoline on a murine orthotopic model of RM9-Luc-PSA prostate cancer was evaluated together with the effect of PD-1 blockade. Concurrent therapy had a beneficial effect, resulting in significantly lower tumor size and weight compared with those in response to monotherapy. Combinational therapy also had a better effect on cell proliferation and microvascular density than did the monotherapy. Additionally, combination therapy is also suggested to enhance antitumor immunity, causing increased numbers of CD44+CD62L+CD8+ memory $\mathrm{T}$ cells and a reduction in the number of immunosuppressive myeloid-derived suppressor cells (MDSCs) in peripheral blood of 
C57BL/6 mice, although the same effect was not observed when mice were treated with nitroxoline alone (Xu et al., 2019).

Decreased cyclin D1 mRNA expression was also observed in human cholangiocarcinoma cell lines HuCCT1 and Huh28 following treatment with nitroxoline, using a real-time polymerase chain reaction (qPCR). In contrast, nitroxoline increased expression of p21 mRNA. In human cholangiocarcinoma cell lines HuCCT1 and Huh28, nitroxoline reduced cell survival significantly and inhibited cell proliferation in a dose- and time-dependent manner (Chan-On et al., 2015).

Forkhead box protein M1 (FOXM1) has been also recognized as target for nitroxoline antitumor activity (Chan-On et al., 2015). FOXM1 is an oncogenic transcription factor belonging to the Forkhead box (FOX) family, with a conserved winged-helix DNA-binding domain or forkhead domain (Bach et al., 2018; Koo et al., 2012). Proteins from the FOX family play an important regulatory role during embryogenesis and development (Bach et al., 2018) and are commonly upregulated in various types of cancer (Bach et al., 2018; Koo et al., 2012). FOXM1 is among the genes upregulated already during the early stages of cancer development and participates in cancer initiation, cell proliferation, cell cycle progression, cell differentiation, DNA damage repair, senescence, tissue homeostasis, metabolism, cancer progression, invasion, angiogenesis and apoptosis. Moreover, dysregulation of FOXM1 is linked with the development of cancer drug resistance (Koo et al., 2012; Bach et al., 2018). Due to its regulatory role, during cancer progression FoxM1 constitutes an important target in cancer treatment (Bach et al., 2018). Treatment with nitroxoline at 20,30 and $40 \mu \mathrm{M}$ significantly reduced both FOXM1 mRNA and protein levels in vitro on HuCCT1 cells in dose- and time-dependent manners as was shown using qPCR and western blot analysis. Moreover, decreased mRNA expression in downstream target genes of FOXM1 including CENP-B, Cdc25B and cell surviving was observed in HuCCT1 cells (Chan-On et al., 2015).

In line with the previously noted studies, nitroxoline significantly reduced cell migration of human cholangiocarcinoma cell lines HuCCT1 in vitro, as shown in a wound healing assay (Chan-On et al., 2015). In the same study, the authors evaluated the expression of matrix metalloproteinase (MMP)-2 and MMP-9 as important enzymes involved in tumor cell migration and invasion, whose expression is among others regulated by FOXM1. Nitroxoline reduced expression of MMP-2 and MMP-9 in HuCC1 cells compared to untreated cells. This could further explain the effect of nitroxoline on tumor cell migration. In addition to regulating MMP-2 and MMP-9 expression through FOXM1 inhibition, direct interaction of nitroxoline with the catalytic domains of MMP-2 and MMP-9 is suggested in molecular docking studies (ChanOn et al., 2015).

Furthermore, nitroxoline appeared as a hit in a drug repurposing strategy (Jiang et al., 2017) that uses a bromodomain-containing protein 4 (BRD4)-specific score based virtual screening protocol termed BRD4LGR (Xing et al., 2017; Jiang et al., 2017).

BRD4 is a member of the bromodomain and extraterminal (BET) family of proteins, (Jung et al., 2015) that contains two conserved tandem bromodomain motifs (BD1 and BD2) (White et al., 2019; Fu et al., 2015; Jung et al., 2015). It is expressed ubiquitously and is required for maintenance of chromatin stability. It controls progression of the cell cycle. In cancer, BRD4 is dysregulated and contributes to changes in the chromatin remod- eling and gene transcription that mediate tumorogenesis (White et al., 2019; Jung et al., 2015). By phosphorylation it stimulates RNA polymerase II and regulates the transcription of various oncogenes that include c-Myc, cyclin dependent kinase 6 (CDK6), one of the essential oncogenes in various types of cancer, and Bcl-2 (Jung et al., 2015). Together, changes in BRD4 in cancer result in cell cycle arrest at the G1 phase and cell apoptosis.

Nitroxoline binds to the first bromodomain of BRD4 (BRD4_BD1), improving its stability. It has further been shown to be a selective BET inhibitor, not affecting other non-BET bromodomain containing proteins. The mechanism of action and its specificity for BDR4 were accounted from the crystal structure of nitroxolineBRD4_BD1 complex. By inhibiting BRD4, nitroxoline inhibits the proliferation of MLL leukemia cell lines through the induction of G1 cell cycle arrest and apoptosis. Moreover, treatment with nitroxoline resulted in dose-dependent repression of c-Myc, one of the downstream genes of the BET family (Jiang et al., 2017).

Nitroxoline was recently shown to be an effective antitumor agent in both pancreatic and small-cell lung cancers (SCLC) (Veschi et al., 2018; Yu et al., 2019). In both cases, it impaired cell viability (Veschi et al., 2018; Yu et al., 2019), decreasing that of pancreatic cell lines AsPC-1, Capan-2 and BxPC-3. It affected the cell cycle distribution, reducing the expression of the proteins cyclin D3 and cyclin B1 involved in the cell cycle. It also impaired the clonogenic activity of all three cell lines (Veschi et al., 2018). Its effect on the cell cycle following nitroxoline treatment was more evident at higher concentrations (40 $\mu \mathrm{M})$ (Veschi et al., 2018). Its antitumor ability was further improved when nitroxoline was used in combination with nelfinavir (Veschi et al., 2018), a competitive inhibitor of HIV aspartyl protease, and, in combination with other antiretroviral drugs, in treating HIV infection (Moyle et al., 1998). Concurrent treatment with both compounds resulted in a dose- and cell-dependent synergistic effect on cell viability, an effect on the cell cycle and on the induction of apoptosis, further impairing the clonogenic activity of pancreatic cell lines (Veschi et al., 2018).

Further, in SCLC cell lines, nitroxoline effectively inhibited cell survival and induced cell apoptosis by suppressing anti-apoptotic proteins such as Bcl-2 and Mcl1 and upregulating proapoptotic protein $\operatorname{Bim}(\mathrm{Yu}$ et al., 2019). The same proteins were identified as being affected by nitroxoline in other types of cancer also (Mao et al., 2017; $\mathrm{Xu}$ et al., 2019). Mechanistic studies revealed that nitroxoline in SCLC significantly downregulates protein levels of the proto-oncogene human homologue of mouse double minute 2 (MDM2) by inducing protease degradation. As a result of MDM2 downregulation by nitroxoline, p53 was upregulated ( $\mathrm{Yu}$ et al., 2019). MDM2 is an E3 ubiquitin ligase localized in the nucleus that is overexpressed in a number of tumors, including SCLC, and plays an important role in tumor development and progression. MDM2 promotes tumor progression by negatively regulating the well-known tumor suppressor p53. MDM2 induces p53 degradation by promoting polyubiquitination that induces proteasome degradation of p53 (Yu et al., 2019; Javid et al., 2015; Michael \& Oren, 2003; Rayburn et al., 2005).

\section{NITROXOLINE DERIVATIVES}

To further improve nitroxoline antitumor activity a number of novel derivatives with various substituents, 
A

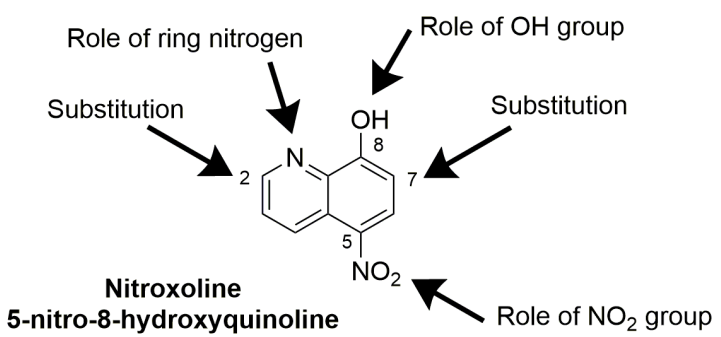

B

Organoruthenated nitroxoline

Inhibitoror of endotheial cell proliferation MetAP2 inhibitor Sirt1 inhibitor<smiles>CN(C)S(=O)(=O)Oc1ccc([N+](=O)[O-])c2ncccc12</smiles>

Compound 48

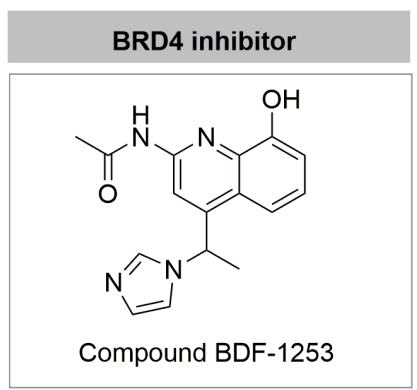

Figure 2. Structures of nitroxoline and its derivatives.

(A) The structure of nitroxoline with the most important positions for structural modification indicated. (B) The nitroxoline derivatives most potent for specific targets - compound 17 (Sosič et al., 2013), compound 48 (Bhat et al., 2012) and compound BDF-1253 (Chen et al., 2018).

using structure-based chemical synthesis, have been prepared (Fig. 2).

Nitroxoline derivatives were prepared with the aim of improving its activity against cathepsin B (Mirković et al., 2011; Sosič et al., 2013, 2018; Mitrović et al., 2017). Evaluation of new compounds with structural modifications on various positions of the nitroxoline scaffold revealed the structural requirements for cathepsin B inhibition (Mirković et al., 2011; Sosič et al., 2013, 2018; Mitrović et al., 2016, 2017). The nitro group at position 5 of nitroxoline was identified as essential for nitroxoline binding to cathepsin $\mathrm{B}$, its absence resulting in loss of cathepsin B inhibition. Also, a hydroxyl group at position 8 on the nitroxoline scaffold is necessary for potent inhibition of cathepsin B endopeptidase activity (Mirković et al., 2011; Sosič et al., 2013). On the other hand, the presence of a larger, saturated lipophilic substituent at position 8 resulted in improved inhibition of cathepsin B exopeptidase activity (Sosič et al., 2013; Mitrović et al., 2016). From the crystal structure of nitroxoline-cathepsin $\mathrm{B}$ complex it can be seen that the position 7 of nitroxoline ring is exposed towards the S1' subsite of cathep$\sin \mathrm{B}$ that favors hydrophobic interactions. Substituents, mostly lipophilic, were therefore made at that position. (Sosic et al., 2013). Moreover, absence of the ring nitro- gen did not impair inhibition of the endopeptidase activity of cathepsin B, while its exopeptidase activity was improved when compared to that of the compounds with the same substituents at other positions (Sosič et al., 2013). Additional structural modifications of the nitroxoline scaffold revealed that, for effective binding into the active site of cathepsin B, both rings are needed (Sosic et al., 2018). Also, in most cases, addition of small substituents at position 2 led to diminished inhibitory activity and an additional nitro group at position 7 also resulted in loss of cathepsin B inhibition (Sosič et al., 2018). Of all the nitroxoline derivatives prepared, the compound with a 2-(ethylamino)acetonitrile group at position 7 of the nitroxoline scaffold (compound 17, Fig. 2) was the most effective for cathepsin B inhibition. It exhibited an 8 -fold increase in inhibition of cathepsin B endopeptidase activity over that of nitroxoline and was also selective for cathepsin B over cathepsins L and H (Sosic et al., 2013). The compound was, therefore, evaluated further for its antitumor activity (Sosič et al., 2013; Mitrović et al., 2017). It showed higher activity than did nitroxoline for inhibition of tumor cell invasion and migration in vitro on cell lines in both two-dimensional and three dimensional models as well as in in vivo on tumor mice model compound 17 showed improved inhibition of 
tumor growth compared to the nitroxoline (Mitrović et al., 2017). Taken together these results show that the nitroxoline scaffold can be used as a starting point for the synthesis of novel compounds with improved pharmacological characteristics (Mitrović et al., 2017).

A number of nitroxoline derivatives were then synthesized and assayed in attempts to improve its antiangiogenic activity. Structural modifications of 8-hydroxyquinoline scaffold led to compounds with increased potency against human umbilical vein endothelial cells (HUVEC) with different mechanisms of action, due not only to their improved inhibition of MetAP2 and SIRT1. In general, inhibition of HUVEC proliferation due to specific inhibition of MetAP2, was observed following the addition of amino substituents at position 7 of the nitroxoline scaffold. Interestingly, minor structural modification of nitro group to nitroso led to increased inhibition of HUVAC proliferation. However, the mechanism of action for this compound was also changed, since this structural modification resulted in loss of inhibitory activity against MetAP2 and also decreased the inhibition of SIRT1. Inhibition of HUVEC proliferation was additionally increased on further reduction of the nitro to an amino group while the activities of MetAP2 and SIRT1 were still not affected. This indicates that this structural modification results in a new mechanism of action. Addition of long-chain alkyl substituents to the amino group did not affect the inhibition of HUVEC proliferation, while acetylation of amino derivatives in general resulted in loss of activity for HUVAC proliferation and MetAP. The exception is the benzamide derivative, which displayed improved inhibition of SIRT1 and higher potency against HUVEC proliferation compared to that of nitroxoline and also inhibited MetAP1. Due to moderate inhibition of MetAP1 the benzamide derivative was suggested to act also on other separate targets beside SIRT1. Next, the 8-hydroxy group of nitroxoline was identified as the only functional group in nitroxoline whose derivatization does not reduce its bioactivity. Esterification of 8-hydroxy group of nitroxoline did not affect the latter's activity against HUVEC proliferation and MetAP2, whereas a derivative with sulfamate at position 8 (Compound 48, Fig. 2) was an even more potent inhibitor of the proliferation of HUVEC and SIRT1 and retained the same potency for inhibition of MetAP2 activity as nitroxoline. It was also the most potent inhibitor among these series of derivatives. However, when the hydroxy group was transformed into a sulfonamide group, new derivatives still inhibited HUVEC proliferation but lost their activity for MetAp2 and SIRT1 inhibition. Taken together, small structural modifications of nitroxoline scaffold resulted in a number of potent but mechanistically distinct derivatives for endothelial cell proliferation inhibition (Bhat et al., 2012).

In addition a novel series of nitroxoline derivatives with improved potency of inhibition of BET proteins and that bound competitively to the BRD4-BD1, were prepared (Chen et al., 2018; Xing et al., 2019). Structural modifications of nitroxoline derivatives effective as BET inhibitors (Chen et al., 2018; Xing et al., 2019) differed from those reported for cathepsin B inhibition (Mirković et al., 2011; Sosič et al., 2013, 2018; Mitrović et al., 2017). Preparation of the first nitroxoline derivatives for BET inhibition showed that, here, introduction of additional hydroxyl group to the nitroxoline ring had a favorable effect. Next, at the position 7 of nitroxoline scaffold, the acetamide group had a beneficial effect, improving the potency of new derivatives. Improvement in inhibition was also observed if 8-hydroxyquinoline and smaller ring at the position 4 were separated by a methylene group. Addition of a third nitrogen atom into the smaller fivemembered ring decreased the potency of derivatives. The crystal structures of BRD-BD1 and nitroxoline derivatives complexes showed the formation of a hydrogen bond, important for binding between the inhibitor and the enzyme. The most potent inhibitor (BDF-1253, Fig. 2) efficiently suppressed the cell viability of RCC cells in vitro, but only a little of non-tumor cells such as HUVEC and RCTEC. Treatment with the compound BDF-1253 resulted in reduced tumor size and c-Myc expression in vivo on an RCC xenograft mice model. The new derivative also induced cell cycle arrest and apoptosis of RCC cell lines, as well as decreased mRNA levels of downstream effectors of BRD4 which are associated with cancer development, including c-Myc, Bcl-2 and CDK6 (Chen et al., 2018). In another study, a BRD4specific score based virtual screening protocol named BRD4LGR was used to analyze the structure-activity relationship (SAR) and derivative optimization of a series of nitroxoline derivatives with improved permeability and physiochemical properties (Xing et al., 2019). Compound analysis showed that, to retain activity, the ring nitrogen should not be substituted. Similarly, as noted for the first group of nitroxoline derivatives as BET inhibitors, also in this series of derivatives substitution at position 4 of the nitroxoline scaffold is suggested to be essential for their binding affinity. Interestingly, the binding modes obtained by residue-based BRD4LGR revealed that substitution at position 2 decreases the possibility of the compound being a potent BRD4 inhibitor, since it disturbs the interaction between the 8-hydroxyl group and the structural water molecules in the enzyme structure. These compounds have been further optimized in order to improve their membrane permeability. More hydrophobic groups were introduced to the hydroxyl group, in order to preserve hydrogen bonds with a structural water molecule, that is crucial for BDR4 binding. Selected compounds showed improved antiproliferative capacity against BRD4 sensitive cancer cell lines and downregulated $\mathrm{c}-\mathrm{Myc}$ in a dose dependent manner (Xing et al., 2019).

Organoruthenium complexes with nitroxoline (Fig. 2) and its derivatives were identified as providing another strategy for improving its antitumor activity. Enzyme kinetic and microscale thermophoresis data showed that new organoruthenium derivatives of nitroxoline and its derivatives inhibit both cathepsin B endo- and exopeptidase activity. Moreover, they significantly impaired processes of tumor progression, such as degradation of ECM and tumor cell invasion in vitro in cell-based functional assays at low, non-cytotoxic concentrations indicating their action on specific target. Generally, metallodrugs improved cathepsin B inhibition and decreased both degradation of ECM and tumor cell invasion compared to those of free ligands (Mitrović et al., 2019).

The antitumor properties of nitroxoline could be further improved by its incorporation into metal-organic nanoparticles composed of bovine serum albumin (BSA), $\mathrm{Cu}^{2+}$ and nitroxoline as an anticancer agent $(\mathrm{BSA} / \mathrm{Cu}$ / NQ nanoparticles). Formation of nanoparticles improved their cell uptake and internalization by cancer cells and their distribution to lysosomes, increasing cytotoxicity against mouse breast cancer cells 4T1 more than by nitroxoline alone or by a complex of nitroxoline and $\mathrm{Cu}(\mathrm{II})$. Further, metal-organic nanoparticles also improved antitumor properties of nitroxoline in an orthotopic 4T1 breast cancer mouse model, without causing systemic toxicity (Hu et al., 2018). 
Taken together, structure-based chemical synthesis leads to a number of new derivatives with different structural modifications of the nitroxoline scaffold. Biochemical evaluation of new derivatives has helped in understanding structure-activity relationships and have demonstrated that different modifications are preferred for different targets and that these findings could be helpful for improving the selectivity of target therapy. In addition to repurposing nitroxoline for use in anticancer therapy, nitroxoline also constitutes a good lead molecule for the development of new derivatives with improved activity and selectivity towards selected targets.

\section{CONCLUSION}

The need for new and effective antitumor drugs with less severe off-target effects, together with the aim of decreasing the cost of their development and clinical evaluation, increase the interest in already established drugs and their repurposing for treatment of cancer. Several independent studies have identified nitroxoline as a very promising candidate for its repurposing from antimicrobial use to antitumor treatment. The antitumor activity of nitroxoline have been demonstrated on a wide range of tumor models, and the different molecular mechanisms of its action in impairing tumor progression established. Moreover, nitroxoline has also been used as a lead compound in the development of new derivatives with improved potency and selectivity for its targets. In conclusion, the findings during the last decade have increased attention for the use of nitroxoline as an antitumor agent. It is to be expected that further studies will focus on clinical evaluation of its newly developed application and demonstrate that the repurposing of old drugs for anticancer treatment is an appropriate strategy for obtaining more effective antitumor drugs.

\section{Acknowledegments}

The authors thank prof. Roger Pain for critical reading of the manuscript.

\section{Competing interests}

The authors have no competing interests to declare.

\section{REFERENCES}

Abouelhassan Y, Yang Q, Yousaf H, Nguyen MT, Rolfe M, Schultz GS, Huigens RW (2017) Nitroxoline: a broad-spectrum biofilmeradicating agent against pathogenic bacteria. Int. J. Antimicrob. Agents 49: 247-251. https://doi.org/10.1016/j.ijantimicag.2016.10.017

Almeida PC, Nantes IL, Chagas JR, Rizzi CC, Faljoni-Alario a, Carmona E, Juliano L, Nader HB, Tersariol IL (2001) Cathepsin B activity regulation. Heparin-like glycosaminogylcans protect human cathepsin B from alkaline $\mathrm{pH}$-induced inactivation. J. Biol. Chem. 276: 944-951. https://doi.org/10.1074/jbc.M003820200

Bach D-H, Long NP, Luu T-T-T, Anh NH, Kwon SW, Lee SK (2018) The dominant role of forkhead box proteins in cancer. Int. J. Mol. Sci. 19: https://doi.org/10.3390/ijms19103279

Bhat S, Shim JS, Zhang F, Chong CR, Liu JO (2012) Substituted oxines inhibit endothelial cell proliferation and angiogenesis. Org. Biomol. Chem. 10: 2979-2992. https://doi.org/10.1039/c2ob06978d

Brooks CL, Gu W (2009) How does SIRT1 affect metabolism, senescence and cancer? Nat. Rev. Cancer 9: 123-128. https://doi. org/10.1038/nrc2562

Chan-On W, Huyen NTB, Songtawee N, Suwanjang W, Prachayasittikul S, Prachayasittikul V (2015) Quinoline-based clioquinol and nitroxoline exhibit anticancer activity inducing FoxM1 inhibition in cholangiocarcinoma cells. Drug Des. Devel. Ther. 9: 2033-2047. https://doi.org/10.2147/DDDT.S79313

Chang W-L, Hsu L-C, Leu W-J, Chen C-S, Guh J-H (2015) Repurposing of nitroxoline as a potential anticancer agent against human prostate cancer: a crucial role on $\mathrm{AMPK} / \mathrm{mTOR}$ signaling pathway and the interplay with Chk2 activation. Oncotarget 6: 39806-39820. https://doi.org/10.18632/oncotarget.5655

Chen W, Zhang H, Chen Z, Jiang H, Liao L, Fan S, Xing J, Xie Y, Chen S, Ding H, Chen K, Jiang H, Luo C, Zheng M, Yao Z, Huang Y, Zhang Y (2018) Development and evaluation of a novel series of Nitroxoline-derived BET inhibitors with antitumor activity in renal cell carcinoma. Oncogenesis 7: https://doi.org/10.1038/ s41389-018-0093-z

Cherdtrakulkiat R, Boonpangrak S, Sinthupoom N, Prachayasittikul S, Ruchirawat S, Prachayasittikul V (2016) Derivatives (halogen, nitro and amino) of 8-hydroxyquinoline with highly potent antimicrobial and antioxidant activities. Biochem. Biophys. Reports 6: 135-141. https://doi.org/10.1016/j.bbrep.2016.03.014

Dallinga MG, Yetkin-Arik B, Kayser RP, Vogels IMC, Nowak-Sliwinska P, Griffioen AW, van Noorden CJF, Klaassen I, Schlingemann RO (2018) IGF2 and IGF1R identified as novel tip cell genes in primary microvascular endothelial cell monolayers. Angiogenesis 21: 823-836. https://doi.org/10.1007/s10456-018-9627-4

Ehlers T, Furness S, Robinson TP, Zhong HA, Goldsmith D, Aribser J, Bowen JP (2016) Methionine aminopeptidase type-2 inhibitors targeting angiogenesis. Curr. Top. Med. Chem. 16: 1478-1488.

Fong W, To KKW (2019) Drug repurposing to overcome resistance to various therapies for colorectal cancer. Cell. Mol. Life Sci. https:// doi.org/10.1007/s00018-019-03134-0

Fraser RSS, Creanor J (1974) Rapid and selective inhibition of RNA synthesis in yeast by 8-hydroxyquinoline. Eur. J. Biochem. 46: 67-73. https://doi.org/10.1111/j.1432-1033.1974.tb03597.x

Fu L, Tian M, Li X, Li J, Huang J, Ouyang L, Zhang Y, Liu B (2015) Inhibition of BET bromodomains as a therapeutic strategy for cancer drug discovery. Oncotarget 6: 5501-5516. https://doi. org/10.18632/oncotarget.3551

Gocheva V, Zeng W, Ke D, Klimstra D, Reinheckel T, Peters C, Hanahan D, Joyce J a. (2006) Distinct roles for cysteine cathepsin genes in multistage tumorigenesis. Genes Dev. 20: 543-556. https:// doi.org/10.1101/gad.1407406

Gupta SC, Sung B, Prasad S, Webb LJ, Aggarwal BB (2013) Cancer drug discovery by repurposing: Teaching new tricks to old dogs. Trends Pharmacol. Sci. 34: 508-517. https://doi.org/10.1016/j. tips.2013.06.005

Heikel G, Choudhury NR, Michlewski G (2016) The role of Trim25 in development, disease and RNA metabolism. Biochem. Soc. Trans. 44: 1045-1050. https://doi.org/10.1042/BST20160077

Hernandez JJ, Pryszlak M, Smith L, Yanchus C, Kurji N, Shahani VM, Molinski S V. (2017) Giving drugs a second chance: Overcoming regulatory and financial hurdles in repurposing approved drugs as cancer therapeutics. Front. Oncol. 7: 1-8. https://doi.org/10.3389/ fonc. 2017.00273

Hu D, Xu H, Xiao B, Li D, Zhou Z, Liu X, Tang J, Shen Y (2018) Albumin-stabilized metal-organic nanoparticles for effective delivery of metal complex anticancer drugs. ACS Appl. Mater. Interfaces 10: 34974-34982. https://doi.org/10.1021/acsami.8b12812

Illy C, Quraishi O, Wang J, Purisima E, Vernet T, Mort JS (1997) Role of the occluding loop in cathepsin B activity. J. Biol. Chem. 272: 1197-1202. https://doi.org/10.1074/jbc.272.2.1197

Javid J, Mir R, Julka PK, Ray PC, Saxena A (2015) Association of p53 and $\mathrm{mdm} 2$ in the development and progression of non-small cell lung cancer. Tumor Biol. 36: 5425-5432. https://doi.org/10.1007/ s13277-015-3208-6

Jiang H, Taggart JE, Zhang X, Benbrook DM, Lind SE, Ding WQ (2011) Nitroxoline (8-hydroxy-5-nitroquinoline) is more a potent anti-cancer agent than clioquinol (5-chloro-7-iodo-8-quinoline). Cancer Lett. 312: 11-17. https://doi.org/10.1016/j.canlet.2011.06.032

Jiang $\mathrm{H}$, Xing J, Wang C, Zhang H, Yue L, Wan X, Chen W, Ding $\mathrm{H}$, Xie $\mathrm{Y}$, Tao $\mathrm{H}$, Chen Z, Jiang $\mathrm{H}$, Chen $\mathrm{K}$, Chen $\mathrm{S}$, Zheng M, Zhang Y, Luo C (2017) Discovery of novel BET inhibitors by drug repurposing of nitroxoline and its analogues. Org. Biomol. Chem. 15: 9352-9361. https://doi.org/10.1039/c7ob02369c

Joyce JA, Hanahan D (2004) Multiple roles for cysteine cathepsins in cancer. [WWW document]. Cell Cycle 3: 1516-1519. https://doi. org/10.4161/cc.3.12.1289

Jung M, Gelato KA, Fernández-Montalván A, Siegel S, Haendler B (2015) Targeting BET bromodomains for cancer treatment. Epigenomics 7: 487-501. https://doi.org/10.2217/epi.14.91

Koo C-Y, Muir KW, Lam EW-F (2012) FOXM1: From cancer initiation to progression and treatment. Biochim. Biophys. Acta 1819: 2837. https://doi.org/10.1016/j.bbagrm.2011.09.004

Kos J, Mitrović A, Mirković B (2014) The current stage of cathepsin B inhibitors as potential anticancer agents. Future Med. Chem. 6: 1355-1371. https://doi.org/10.4155/fmc.14.73

Kresken M, Körber-Irrgang B (2014) In vitro activity of nitroxoline against escherichia coli urine isolates from outpatient departments in Germany. Antimicrob. Agents Chemother. 58: 7019-7020. https:// doi.org/10.1128/AAC.03946-14

Krupa JC, Hasnain S, Nägler DK, Ménard R, Mort JS (2002) S2' substrate specificity and the role of His110 and His111 in the exo- 
peptidase activity of human cathepsin B. Biochem. J. 361: 613-619. https://doi.org/10.1042/0264-6021:3610613

Kumari N, Thakur N, Cho HR, Choi SH (2019) Assessment of early therapeutic response to nitroxoline in temozolomide-resistant glioblastoma by amide proton transfer imaging: A preliminary comparative study with diffusion-weighted imaging. Sci. Rep. 9: 3-9. https:// doi.org/10.1038/s41598-019-42088-y

Kyrylkova K, Kyryachenko S, Leid M, Kioussi C (2012) Detection of apoptosis by TUNEL assay. Methods Mol. Biol. 887: 41-47. https:// doi.org/10.1007/978-1-61779-860-3_5

Lazovic J, Guo L, Nakashima J, Mirsadraei L, Yong W, Kim HJ, Ellingson B, Wu H, Pope WB (2015) Nitroxoline induces apoptosis and slows glioma growth in vivo. Neuro. Oncol. 17: 53-62. https:// doi.org/10.1093/neuonc/nou139

Lee S-H, Lee J-H, Lee H-Y, Min K-J (2019) Sirtuin signaling in cellular senescence and aging. BMB Rep. 52: 24-34

Liu T, Liu PY, Marshall GM (2009) The critical role of the class III histone deacetylase SIRT1 in cancer. Cancer Res. 69: 1702-1705. https://doi.org/10.1158/0008-5472.CAN-08-3365

Mao H, Du Y, Zhang Z, Cao B, Zhao J, Zhou H, Mao X (2017) Nitroxoline shows antimyeloma activity by targeting the TRIM25/ p53 axle. Anticancer. Drugs 28: 376-383. https://doi.org/10.1097/ CAD.0000000000000466

Mauriz JL, Martín-Renedo J, García-Palomo A, Tuñón MJ, GonzálezGallego J (2010) Methionine aminopeptidases as potential targets for treatment of gastrointestinal cancers and other tumours. Curr. Drug Targets 11: 1439-1457.

Michael D, Oren M (2003) The p53-Mdm2 module and the ubiquitin system. Semin. Cancer Biol. 13: 49-58

Mirković B, Renko M, Turk S, Sosič I, Jevnikar Z, Obermajer N, Turk D, Gobec S, Kos J (2011) Novel mechanism of cathepsin B inhibition by antibiotic nitroxoline and related compounds. ChemMedChem 6: 1351-1356. https://doi.org/10.1002/cmdc.201100098

Mirković B, Markelc B, Butinar M, Mitrović A, Sosič I, Gobec S, Vasiljeva O, Turk B, Čemažar M, Serša G, Kos J (2015) Nitroxoline impairs tumor progression in vitro and in vivo by regulating cathepsin B activity. Oncotarget 6: 19027-42. https://doi.org/10.18632/oncotarget.3699

Mitrović A, Mirković B, Sosič I, Gobec S, Kos J (2016) Inhibition of endopeptidase and exopeptidase activity of cathepsin B impairs extracellular matrix degradation and tumour invasion. Biol. Chem. 397: 165-174. https://doi.org/10.1515/hsz-2015-0236

Mitrović A, Sosič I, Kos S, Tratar UL, Breznik B, Kranjc S, Mirković B, Gobec S, Lah T, Serša G, Kos J (2017) Addition of 2-(ethylamino)acetonitrile group to nitroxoline results in significantly improved anti-tumor activityin vitroandin vivo. Oncotarget 8: 59136-59147. https://doi.org/10.18632/oncotarget.19296

Mitrović A, Kljun J, Sosič I, Uršič M, Meden A, Gobec S, Kos J, Turel I (2019) Organoruthenated nitroxoline derivatives impair tumor cell invasion through inhibition of cathepsin B activity. Inorg. Chem. 58: 12334-12347. https://doi.org/10.1021/acs.inorgchem.9b01882

Mohamed MM, Sloane BF (2006) Cysteine cathepsins: multifunctional enzymes in cancer. Nat. Rev. Cancer 6: 764-775. https://doi. org/10.1038/nrc1949

Moyle GJ, Youle M, Higgs C, Monaghan J, Prince W, Chapman S, Clendeninn N, Nelson MR (1998) Safety, pharmacokinetics, and antiretroviral activity of the potent, specific human immunodeficiency virus protease inhibitor nelfinavir: results of a phase I/II trial and extended follow-up in patients infected with human immunodeficiency virus. J. Clin. Pharmacol. 38: 736-743. https://doi. org/10.1002/j.1552-4604.1998.tb04814.x

Mrhar A, Kopitar Z, Kozjek F, Presl V, Karba R (1979) Clinical pharmacokinetics of nitroxoline. Int. J. Clin. Pharmacol. Biopharm. 17: $476-481$

Musil D, Zucic D, Turk D, Engh RA, Mayr I, Huber R, Popovic T, Turk V, Towatari T, Katunuma N (1991) The refined 2.15 A X-ray crystal structure of human liver cathepsin B: the structural basis for its specificity. EMBO J. 10: 2321-2330

Naber KG, Niggemann H, Stein G, Stein G (2014) Review of the literature and individual patients' data meta-analysis on efficacy and tolerance of nitroxoline in the treatment of uncomplicated urinary tract infections. BMC Infect. Dis. 14: https://doi.org/10.1186/ s12879-014-0628-7

Nägler DK, Storer AC, Portaro FC V., Carmona E, Juliano L, Ménard R (1997) Major increase in endopeptidase activity of human cathepsin B upon removal of occluding loop contacts. Biochemistry 36: 12608-12615. https://doi.org/10.1021/bi971264+

Nowak-Sliwinska P, Scapozza L, Altaba AR i. (2019) Drug repurposing in oncology: Compounds, pathways, phenotypes and computational approaches for colorectal cancer. Biochim. Biophys. Acta-Rev. Cancer 1871: 434-454. https://doi.org/10.1016/j.bbcan.2019.04.005

Ota H, Akishita M, Eto M, Iijima K, Kaneki M, Ouchi Y (2007) Sirt1 modulates premature senescence-like phenotype in human endothelial cells. J. Mol. Cell. Cardiol. 43: 571-579. https://doi.org/10.1016/j. yjmcc.2007.08.008
Oviedo P, Quiroga M, Pegels E, Husulak E, Vergara M (2000) Effects of subinhibitory concentrations of ciprofloxacin on enterotoxigenic Escherichia coli virulence factors. J. Chemother. 12: 487-490. https:// doi.org/10.1179/joc.2000.12.6.487

Pantziarka P, Bouche G, Meheus L, Sukhatme V, Sukhatme VP (2014) The repurposing drugs in oncology (ReDO) project. Ecancermedicalscience 8: 1-13. https://doi.org/10.3332/ecancer.2014.442

Pelletier C, Prognon P, Bourlioux P (1995) Roles of divalent cations and $\mathrm{pH}$ in mechanism of action of nitroxoline against Escherichia coli strains. Antimicrob. Agents Chemother. 39: 707-713. https://doi. org/10.1128/AAC.39.3.707

Qin Y, Cui H, Zhang H (2016) Overexpression of TRIM25 in lung cancer regulates tumor cell progression. Technol. Cancer Res. Treat. 15: 707-715. https://doi.org/10.1177/1533034615595903

Rayburn E, Zhang R, He J, Wang H (2005) MDM2 and human malignancies: expression, clinical pathology, prognostic markers, and implications for chemotherapy. Curr. Cancer Drug Targets 5: 27-41

Roshy S, Sloane BF, Moin K (2003) Pericellular cathepsin B and malignant progression. Cancer Metastasis Rev. 22: 271-86.

Sato Y (2004) Role of aminopeptidase in angiogenesis. Biol. Pharm. Bull. 27: 772-776. https://doi.org/10.1248/bpb.27.772

Shim JS, Matsui Y, Bhat S, Nacev BA, Xu J, Bhang HEC, Dhara S, Han KC, Chong CR, Pomper MG, So A, Liu JO (2010) Effect of nitroxoline on angiogenesis and growth of human bladder cancer. J. Natl. Cancer Inst. 102: 1855-1873. https://doi.org/10.1093/jnci/ djq457

Shim JS, Liu JO (2014) Recent advances in drug repositioning for the discovery of new anticancer drugs. Int. J. Biol. Sci. 10: 654-663. https://doi.org/10.7150/ijbs.9224

Skrzydlewska E, Sulkowska M, Koda M, Sulkowski S (2005) Proteolytic-antiproteolytic balance and its regulation in carcinogenesis (WWW document).

Sleire L, Førde-Tislevoll HE, Netland IA, Leiss L, Skeie BS, Enger PØ (2017) Drug repurposing in cancer. Pharmacol. Res. 124: 74-91. https://doi.org/10.1016/j.phrs.2017.07.013

Sobke A, Klinger M, Hermann B, Sachse S, Nietzsche S, Makarewicz O, Keller PM, Pfister W, Straubea E (2012) The urinary antibiotic 5-nitro-8-hydroxyquinoline (nitroxoline) reduces the formation and induces the dispersal of Pseudomonas aeruginosa biofilms by chelation of iron and zinc. Antimicrob. Agents Chemother. 56: 6021-6025. https://doi.org/10.1128/AAC.01484-12

Sobke A, Makarewicz O, Baier M, Bär C, Pfister W, Gatermann SG, Pletz MW, Forstner C (2018) Empirical treatment of lower urinary tract infections in the face of spreading multidrug resistance: in vitro study on the effectiveness of nitroxoline. Int. J. Antimicrob. Agents 51: 213-220. https://doi.org/10.1016/j.ijantimicag.2017.10.010

Sosič I, Mirković B, Arenz K, Štefane B, Kos J, Gobec S (2013) Development of new cathepsin $\mathrm{B}$ inhibitors: Combining bioisosteric replacements and structure-based design to explore the structureactivity relationships of nitroxoline derivatives. J. Med. Chem. 56: 521-533. https://doi.org/10.1021/jm301544x

Sosič I, Mitrović A, Ćurić H, Knez D, Brodnik Žugelj H, Štefane B, Kos J, Gobec S (2018) Cathepsin B inhibitors: further exploration of the nitroxoline core. Bioorg. Med. Chem. Lett. https://doi. org/10.1016/j.bmcl.2018.02.042

Vasiljeva O, Reinheckel T, Peters C, Turk D, Turk V, Turk B (2007) Emerging roles of cysteine cathepsins in disease and their potential as drug targets. Curr. Pharm. Des. 13: 387-403

Vasiljeva O, Turk B (2008) Dual contrasting roles of cysteine cathepsins in cancer progression: apoptosis versus tumour invasion. Biochimie 90: 380-386. https://doi.org/10.1016/j.biochi.2007.10.004

Veschi S, De Lellis L, Florio R, Lanuti P, Massucci A, Tinari N, De Tursi M, Di Sebastiano P, Marchisio M, Natoli C, Cama A (2018) Effects of repurposed drug candidates nitroxoline and nelfinavir as single agents or in combination with erlotinib in pancreatic cancer cells. J. Exp. Clin. Cancer Res. 37: 1-13. https://doi.org/10.1186/ s13046-018-0904-2

Wagenlehner FME, Münch F, Pilatz A, Bärmann B, Weidner W, Wagenlehner CM, Straubinger M, Blenk H, Pfister W, Kresken M, Naber KG (2014) Urinary concentrations and antibacterial activities of nitroxoline at 250 milligrams versus trimethoprim at 200 milligrams against uropathogens in healthy volunteers. Antimicrob. Agents Chemother. 58: 713-721. https://doi.org/10.1128/AAC.02147-13

White ME, Fenger JM, Carson WE (2019) Emerging roles of and therapeutic strategies targeting BRD4 in cancer. Cell. Immunol. 337: 48-53. https://doi.org/10.1016/j.cellimm.2019.02.001

Wijma RA, Huttner A, Koch BCP, Mouton JW, Muller AE (2018) Review of the pharmacokinetic properties of nitrofurantoin and nitroxoline. J. Antimicrob. Chemother. 73: 2916-2926. https://doi. org/10.1093/jac/dky255

World Health Organization (2019)

Xing J, Lu W, Liu R, Wang Y, Xie Y, Zhang H, Shi Z, Jiang H, Liu Y-C, Chen K, Jiang H, Luo C, Zheng M (2017) Machine-LearningAssisted Approach for Discovering Novel Inhibitors Targeting Bromodomain-Containing Protein 4. J. Chem. Inf. Model. 57: 1677-1690. https://doi.org/10.1021/acs.jcim.7b00098 
Xing J, Zhang R, Jiang X, Hu T, Wang X, Qiao G, Wang J, Yang F, Luo X, Chen K, Shen J, Luo C, Jiang H, Zheng M (2019) Rational design of 5 -((1H-imidazol-1-yl)methyl)quinolin-8-ol derivatives as novel bromodomain-containing protein 4 inhibitors. Eur. J. Med. Chem. 163: 281-294. https://doi.org/10.1016/j.ejmech.2018.11.018

Xu N, Huang L, Li X, Watanabe M, Li C, Xu A, Liu C, Li Q, Araki M, Wada K, Nasu Y, Huang P (2019) The novel combination of nitroxoline and PD-1 blockade, exerts a potent antitumor effect in a mouse model of prostate cancer. Int. J. Biol. Sci. 15: 919-928. https://doi.org/10.7150/ijbs.32259

Yadav V, Talwar P (2019) Repositioning of fluoroquinolones from antibiotic to anti-cancer agents: An underestimated truth. Biomed. Pharmacother. 111: 934-946. https://doi.org/10.1016/j.biopha.2018.12.119

Yu JG, Ji CH, Shi MH (2019) Nitroxoline induces cell apoptosis by inducing MDM2 degradation in small-cell lung cancer. Kaobsiung J. Med. Sci. 202-208. https://doi.org/10.1002/kjm2.12051 